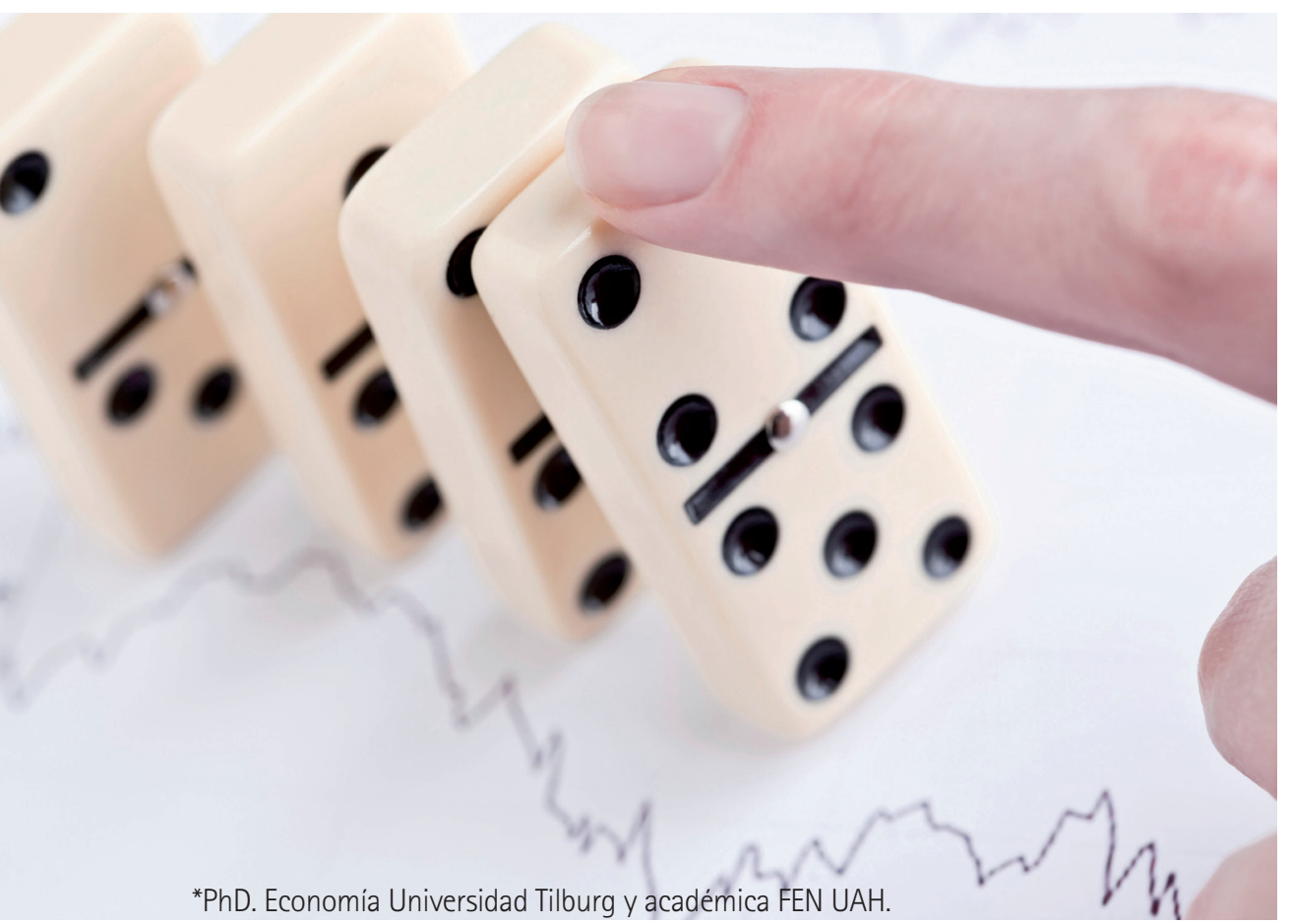

*PhD. Economía Universidad Tilburg y académica FEN UAH.

\section{Radiografía del Riesgo Sistémico en los bancos chilenos}

\section{Por Consuelo Silva Buston*}

El riesgo sistémico es la amenaza de que la quiebra de un banco se propague al resto del sistema financiero provocando la caída de otros bancos. En esta columna queremos entender más profundamente este riesgo en el contexto del sistema financiero chileno.

Un aumento en el riesgo sistémico puede surgir de diversas fuentes. Primero, las instituciones financieras presentan conexiones directas -por ejemplo, por transacciones en el mercado interbancario o de derivadospor lo que un shock a una parte del sistema puede fácilmente extenderse a otros sectores. Segundo, las instituciones financieras también están indirectamente relacionadas. Tienden a llevar a cabo actividades similares o presentan homogeneidad en otras dimensiones -por ejemplo, en sus sistemas de gestión del riesgo o comportamiento en manada (herding)-, las cuales amplifican el impacto de shocks comunes. monitorear el nivel de riesgo sistémico en el sistema financiero. Entre estas medidas se encuentran las correlaciones entre crecimiento de crédito y crecimiento del PIB, y entre préstamos comerciales o de consumo y consumo privado. Estas medidas son útiles para tener una idea general de la salud del sistema financiero. Sin embargo una medida más precisa y a nivel micro puede entregar mejor información para politicas macro prudenciales ${ }^{1}$ de contención de este riesgo.

En esta columna mostramos el riesgo sistémico del sistema chileno con una medida más precisa a nivel de banco. Es decir, buscamos identificar qué bancos se encuentran más interconectados con el resto del sistema financiero, por lo que su hipotética quiebra podría afectar negativamente, con mayor probabilidad, a otros bancos. Cómo proxy de este riesgo a nivel de institución financiera, se usa la medida de riesgo sistémico introducida por Schaeck et al. 2013. Esta medida "limpia" la homogeneidad o conexiones interbancarias que son atribuibles a estrategias de diversificación comunes. Es decir, mide las fuentes de riesgo sistémico que son directas (e.g. transacciones en el mercado interbancario) y la homogeneidad indirecta entre bancos que no corresponde a diversificación (e.g comportamiento de herding o de manada). La ventaja de esta medida entonces, es que mide sólo la parte negativa de dichas interconexiones. Esto dado que una mayor diversificación es un componente positivo en términos de estabilidad pues disminuye la probabilidad de quiebra individual de los bancos. ${ }^{2}$ Idealmente esta proxy se calcula basada en los precios de las acciones de los distintos bancos. Sin embargo, en Chile muy pocas instituciones están listadas en la bolsa. Por lo tanto, usaremos datos contables para su cálculo.

En primer lugar, queremos identificar qué bancos impondrian una mayor amenaza al sistema. Con esta medida, elaboramos un ranking de las distintas instituciones al año 2013 con respecto a su aporte al riesgo sistémico. En la tabla 1 vemos que el mayor aporte lo hace el Banco de Chile, seguido del Banco BICE y CorpBanca, todas instituciones grandes y actores importantes en nuestro sistema. Esta elevada posición en el ranking indica que la eventual caída de estos bancos podría generar fuerte inestabilidad en el sistema financiero chileno. Por el 
contrario, y como es de esperar, los bancos extranjeros son los menos correlacionados con el resto del sistema por lo que su caída no impondría una amenaza considerable.

\begin{tabular}{r|l} 
Ranking & Banco \\
\hline 1 & Banco de Chile \\
2 & Banco BiCE \\
3 & CorpBanca \\
4 & BCI \\
5 & Banco Security \\
6 & Banco Ripley \\
7 & BBVA \\
8 & Banco Santander Chile \\
9 & Banco Falabella \\
10 & Scotiabank Chile \\
11 & Banco Itau Chile \\
12 & Banco Paris \\
13 & Banco de la Nacion Argentina \\
14 & Banco Consorcio \\
15 & Deutsche Bank (Chile) SA \\
16 & Banco Internacional \\
17 & Bank of Tokyo \\
18 & Banco Penta \\
19 & JP Morgan Chase Bank \\
20 & Banco do Brasil S.A. \\
21 & HSBC Bank (Chile) \\
22 & Rabobank Chile
\end{tabular}

¿Qué tipo de bancos entonces podrian imponer una mayor amenaza al sistema? El gráfico 1 muestra el promedio anual de riesgo sistémico por categoría de banco: multigrandes, multimedianos, retail y otros. Un primer punto importante es que la interconexión de los bancos fue la más alta durante el período de crisis 2007-2009, siendo el mayor aporte a este riesgo el de los bancos multigrandes, seguidos por los multimedianos 3 . Se observa también que a pesar de haber disminuido considerablemente después de la crisis, el aporte de este tipo de bancos al riesgo sistémico ha aumentado durante los últimos años, no así los otros bancos (principalmente los bancos extranjeros) quienes presentan una menor volatilidad en sus niveles de riesgo a lo largo del tiempo. Por lo tanto, los reguladores deberian poner especial atención en el monitoreo de los bancos multigrandes y multimedianos. Afortunadamente, el sistema financiero chileno es robusto y bastante estable, y pese a que los niveles de riesgo aumentaron durante la crisis, el sistema no se vio muy afectado gracias a los altos niveles de capitalización (y que aún se mantienen) de los bancos en el país.

En línea con la evidencia encontrada para otros países, el tamaño de los bancos jue-

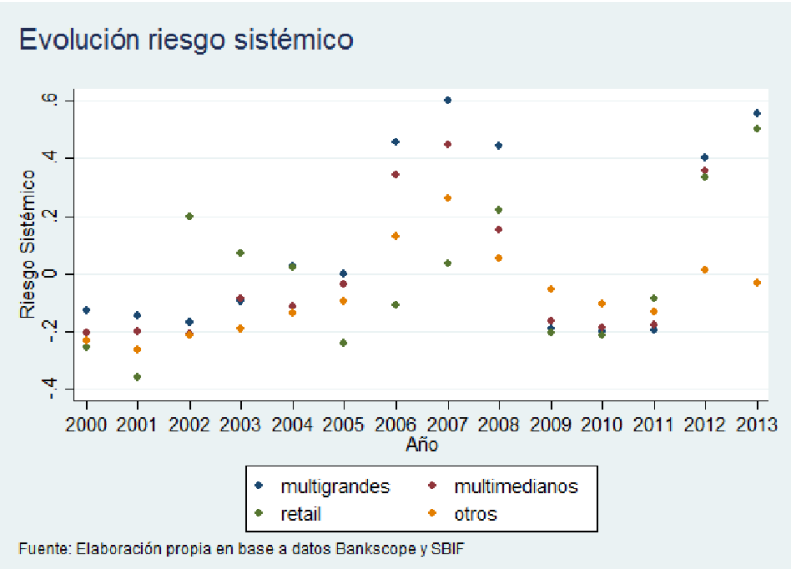

Gráfico 1

Riesgo Sistémico y tamaño

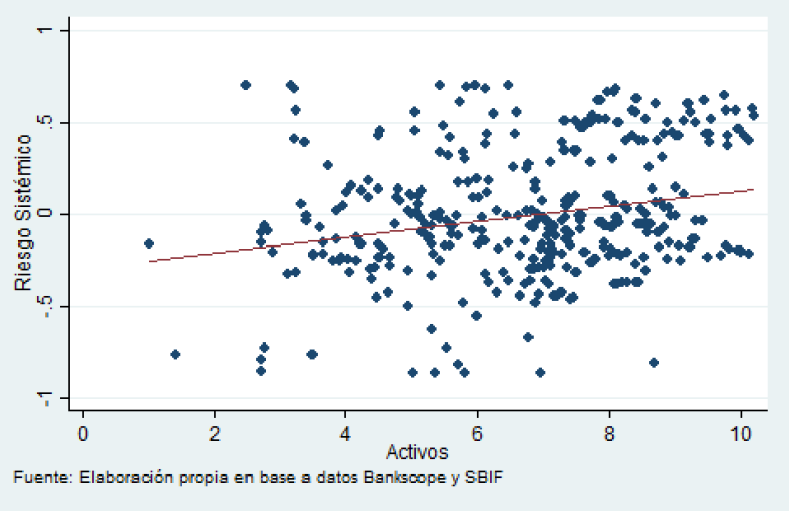

Gráfico 2

Oe

ga un rol importante en el nivel de riesgo que imponen al sistema. Esta relación es ilustrada en el gráfico 2. Como vemos, parece haber una relación positiva entre tamaño del banco, medido como el total de sus activos (en billones de US\$), y el riesgo que imponen al sistema. Este resultado es intuitivo: bancos más grandes tienen, por ejemplo, un rol protagónico en los mercados interbancarios y son importantes actores en los mercados de derivados. En este sentido parecen necesarias, también en el contexto chileno, las medidas propuestas por reguladores internacionales con respecto a resguardos adicionales, como mayores requerimientos de capital para los bancos de mayor tamaño.

Esta primera radiografía del riesgo sistémico en el sistema bancario chileno deja de manifiesto que se debe instalar esta discusión en la agenda regulatoria y destaca la importancia de que mejoras en la medición de riesgo sistémico es un primer paso para avanzar en la calidad de las reformas en la regulación bancaria. Si bien en Chile se han dado pasos para avanzar en la regulación bancaria -se creó un Consejo de Estabilidad Financiera-, y las entidades reguladoras se encuentran activamente analizando los próximos pasos a seguir para ponernos al dia con respecto a la agenda regulatoria, aún estamos considerablemente atrasados con respecto a el monitoreo de este riesgo en relación a paises desarrollados.

\footnotetext{
${ }^{1}$ Aquellas políticas tendientes a limitar riesgos financieros sistémicos.

${ }^{2}$ Schaeck, Silva Buston, Wagner 2013 The Two Faces of Interbank Correlation, EBC Discussion Paper; Vol. 2013-015.

${ }^{3}$ Este incremento en el riesgo durante este periodo también fue mostrado por Avanzini y Jara (2013).
}

\section{Observatorio Económico >}

Decano: Jorge Rodríguez Grossi Fono Facultad: 28897366 e-mail: jrodrigu@uahurtado.cl fen.uahurtado.cl 